ectomy and complete remission occurred in patients with no germinal centres and a short history of disease. Indeed electromyographic studies showed immediate postoperative improvement in $60 \%$ of patients with no germinal centres and short duration of symptoms, whereas no immediate improvement was seen in patients with many germinal centres and a long history. They regard their findings as an indication for early thymectomy, while the disease is still in its mild stages. Since young patients have a higher incidence of germinal centres in the thymus thymectomy is particularly relevant to this age group-and as long ago as 1958 Simpson $^{7}$ stated that the best response to thymectomy was in young patients with a short history of disease. Furthermore thymectomy arrests the progress of the disease even when it fails to induce remission, so that early operation should reduce the number of patients developing the more severe forms of myasthenia. Similarly, in those patients with tumours of the thymus early operation is also indicated: the longer the duration of symptoms before surgery the greater the incidence of malignant change in the tumour.

Most of the conclusions reached by the Mount Sinai group will receive general acceptance, as they support what has been a clinical impression for some time. Similarly their recommendation that corticosteroids should follow and not precede thymectomy is sound advice. More controversial, however, is their claim that thymectomy via the transcervical approach should be regarded as the treatment of choice, owing to its low morbidity and negligible mortality. The low morbidity and mortality is surely due to the advances in anaesthesia and assisted respiration, which are now just as much features of the traditional approach through the sternum; and the traditional approach retains its advantage-the surgeon can actually see what he is doing.

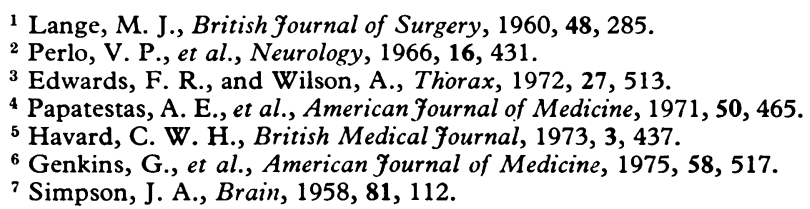

\section{The Mite and Childhood Asthma: Myth or Menace?}

Is the house-dust mite really a major allergen and responsible for symptoms in children with allergic asthma? Any such claims demand careful consideration as asthma is the commonest handicapping disease of childhood; the most recent British survey ${ }^{1}$ showed that about 1 in 20 schoolchildren suffered from the disease. An allergic component can be shown in the vast majority of cases by positive reactions to simple skin tests with common known allergens. Frequencies of positive skin tests as high as $80 \%$ to house-dust and housedust mite have been recorded in several surveys of asthmatic children..$^{2-4}$ But what further evidence is there to establish the mite as a major offending allergen, such as the evidence which already exists for grass pollen? Positive evidence should include opportunities for exposure, evidence of clinical sensitization, and the effectiveness of specific therapy.

The association of the mite Dermatophagoides spp. with human environs has now been established throughout the world. ${ }^{5-7}$ The highest levels of infestation occur in the home, especially in the dust of beds and bedrooms $;^{8}$ lower levels have been found in institutions such as hospitals. ${ }^{6}$ The particular distribution of the mite probably reflects its needs for human skin scales as a food source and its preference for warmth and humidity. ${ }^{7}$ Fortunately it does not parasitize the human body.

Evidence that asthmatic children readily become sensitized to the house-dust mite has accumulated from studies using skin tests, nasal and bronchial provocation tests, and the detection of mite-specific IgE in sera. ${ }^{2}$ It has also been shown that sensitization may occur as early as the second year of life, ${ }^{2}$ probably as a result of the ample opportunities for early exposure to this ubiquitous allergen. The extrapolation of data obtained from these somewhat indirect methods to the incrimination of the mite as a major cause of allergic wheezing may, however, be questioned. Comparison with grass pollen hypersensitivity is again useful. Very small amounts of either allergen when inhaled can provoke symptoms in sensitive subjects; indeed McAllen et al. ${ }^{9}$ estimated from quantitative bronchial challenge tests that allergenic material weighing less than one whole live mite could provoke an acute attack of asthma. Furthermore the measured serum levels of specific IgE provoked by these two allergens have been found to be roughly equivalent. ${ }^{10}$ Mite allergy should, therefore, be considered as a factor in the causation of wheezing in childhood.

Therapy directed against any specific allergy must firstly aim at avoidance of the offending allergen. Complete eradication of the mite allergen is clearly impossible. A reduction in levels of mite infestation by the use of known chemical pesticides is already feasible, but the safety of these agents for asthmatic patients has yet to be established. A further problem is that the remains of dead mites and mite faeces and secretions retain their allergenicity. At present practical efforts at reducing inhalation of mite dust are limited to simple hygienic measures in the childs bedroom. These include regular vacuum cleaning, the use of synthetic bedding material, which should be washed frequently, and the enclosure of the mattress in an impervious cover. In a recently reported trial of the effectiveness of such avoidance measures Sarsfield and his colleagues $^{11}$ in Leeds showed that they can indeed greatly reduce the incidence of asthmatic attacks in mite-sensitive children. These cheap and harmless measures certainly warrant an initial trial in all asthmatic children with evidence of mite sensitivity.

A few trials of hyposensitization to the mite, using various dosage schedules and preparations, have so far been reported. ${ }^{12-18}$ Their results indicate only limited success. The effectiveness of commercially available preparations has not yet been supported by clinical trials in mite-sensitive asthmatic children. Until these are reported, they cannot be recommended for routine therapy.

${ }^{1}$ Dawson, B., et al., Lancet, 1969, 1, 827.

2 Sarsfield, J. K., Archives of Disease in Children, 1974, 49, 711

${ }^{3}$ Smith, J. M., et al., British Medical fournal, 1969, 2, 723.

Bullock, J. D., and Frick, O. L., American fournal of Diseases of Children, 1972, 123, 222.

5 Voorhorst, R., Spieksma-Boezeman, M. I. A., and Spieksma, F. Th. M., Allergie und Asthma, 1964, 10, 329.

6 Blythe, M. E., et al., British Medical fournal, 1975, 1, 62.

7 Bronswijk, van J. E. M. H., and Sinha, R. N., Fournal of Allergy, 1971, 47, 31.

${ }^{8}$ Maunsell, K., Wraith, D. G., and Cunnington, A. M., Lancet, 1968, 1, 1267

${ }^{9}$ McAllen, M. K., Assem, E. S. K., and Maunsell, K., British Medical fournal, 1970, 2, 501.

10 Stenius, B., et al., Clinical Allergy, 1971, 1, 37.

11 Sarsfield, J. K., et al., Archives of Disease in Childhood, 1974, 49, 716

12 Voorhorst, R., and Spieksma, Th. F. M., Acta Allergologica, 1969, $24,115$.

${ }^{13}$ Munro-Ashman, D., et al., Excerpta Medica, 1970, 211, 139

14 Maunsell, K., Wraith, D. G., and Hughes, A. M., Lancet, 1971, 1, 967.

15 Smith, A. P., British Medical fournal, 1971, 4, 204.

16 D'Souza, M. F., et al., Clinical Allergy, 1973, 3, 177.

17 Smith, J. M., and Pizarro, Y. A., Clinical Allergy, 1972, 2, 281.

18 Taylor, B., Sanders, S. S., and Norman, A. P., Clinical Allergy, 1974, 4, 35. 